\title{
Risk Spillover between the US and the Remaining G7 Stock Markets Using Time-Varying Copulas with Markov Switching: Evidence from Over a Century of Data
}

\author{
Qiang Ji ${ }^{\text {a,b,*, }}$, Bing-Yue Liu ${ }^{\mathrm{c}}$, Juncal Cunado ${ }^{\mathrm{d}}$ and Rangan Gupta ${ }^{\mathrm{e}}$ \\ ${ }^{a}$ Center for Energy and Environmental Policy Research, Institutes of Science and Development, \\ Chinese Academy of Sciences, Beijing 100190, China \\ b School of Public Policy and Management, University of Chinese Academy of Sciences, Beijing \\ 100049, China \\ ${ }^{c}$ School of Economics \& Management, Beihang University, Beijing 100191, China \\ ${ }^{\mathrm{d}}$ University of Navarra, School of Economics, Edificio Amigos, E-31080 Pamplona, Spain \\ e Department of Economics, University of Pretoria, Pretoria 0002, South Africa
}

* Corresponding author at: Center for Energy and Environmental Policy Research, Institutes of Science and Development, Chinese Academy of Sciences, Beijing 100190, China.

E-mail addresses: jqwxnjq@163.com (Q. Ji), jcunado@unav.es (J. Cunado), rangan.gupta@up.ac.za (R. Gupta).

Abstract: This paper analyses the risk spillover effect between the US stock market and the remaining G7 stock markets by measuring the conditional Value-at-Risk (CoVaR) using time-varying copula models with Markov switching and data that covers more than 100 years. The main results suggest that the dependence structure varies with time and has distinct high and low dependence regimes. Our findings verify the existence of risk spillover between the US stock market and the remaining G7 stock markets. Furthermore, the results imply the following: 1) abnormal spikes of dynamic CoVaR were induced by well-known historical economic shocks; 2) The 
value of upside risk spillover is significantly larger than the downside risk spillover and 3) The magnitudes of risk spillover from the remaining G7 countries to the US are significantly larger than that from the US to these countries.

Keywords: Time-varying copula; Markov switching; CoVaR; risk spillover; G7 stock markets.

JEL Classification: C21, C28, G32, G38.

\section{Introduction}

Since the mid-1990s, financial markets have been hit by a number of crises, including the 1994 Mexican peso collapse, which affected many Latin American countries; the 1997 Thai crisis, which ignited the East Asian crisis; the 1998 Russian crisis, which affected Mexico and other Latin American countries; the 1999 Brazilian devaluation; the 2001 crises in Argentina and Turkey and the global financial crisis of 2008-09 triggered by the US subprime crisis in August 2009. One characteristic of these recent crises is their quick and violent spread across several countries (Edwards, 2000; Kodres and Pritsker, 2002; Forbes and Rigobon, 2002; Karolyi, 2003; Bekaert et al., 2005; Ozcan and Unsal, 2012). Due to this spillover, and in the wake of the recent global crisis, a growing interest in measuring systemic risk can be observed in the literature.

While Value-at-Risk (VaR) is the most common risk measure used to calculate the risk of an isolated individual institution (Kupiec, 2002; Jorion, 2006), the nature of previous financial crises led scholars to question the appropriateness of that measure to serve as a proxy for the 'risk that the stability of the financial system as a whole is threatened' and prompted the use of other measures, such as Conditional Value-at-Risk (CoVaR) (Adrian and Brunnermeier, 2011). In addition, the Basel Committee has 
established and adapted different regulatory capital requirements in order to address this systemic risk (see the Basel Accords, Basel I, Basel II and Basel III).

Studying the interdependence among financial institutions or systems is not only important from a regulatory point of view (Kashyap et al., 2008; Brunnermeier et al., 2009; Nier, 2009) but also for portfolio decisions (Ang and Bekaert, 2002; Aït-Sahalia and Hurd, 2016), hedging strategies (Balcilar et al., 2016), patterns of market integration (Bekaert and Harvey, 2003; Bartram et al., 2007) and the degree of contagion or spillover (Bae et al., 2003; Bae and Zhang, 2015; Lehkonen, 2015). In this context, the objective of this paper is to analyse the effect of risk spillover between the US stock market and the remaining G7 stock markets using data from more than 100 years.

According to the literature, there are different channels through which financial shocks spread across countries and raise the systemic risk of the system (see Roubini, 2003 for a survey), such as trade linkages (Corsetti et al., 1999; Forbes, 2012; Pritsker, 2001), competitive devaluations (Corsetti et al., 1999), 'wake-up calls' (Forbes, 2012; Ahnert and Bertsch, 2015) or the 'common lender' effect (Van Rijckeghem and Weder, 2001; Forbes, 2012; Bekaert et al., 2014). Through the first two channels, devaluation that occurs in a crisis-stricken country reduces the export competitiveness of the countries with which it competes in third markets, which can also put pressure on the currencies of other countries. Consistent with the 'wake-up calls' theory, a financial crisis in country 1 is a call for investors in country 2 to acquire information about the risk of exposure to a macro shock in that country 2 (see Anhert and Bertsch, 2017 for more on the wake-up theory of contagion). Finally, following Kaminsky and Reinhart 
(1999), the common lender effect asserts that a country with the same lender as a country already hit by a crisis is more likely to experience a financial crisis. Based on the economic and financial literature, the stock market dependence among different countries could be explained by different linkages, such as the volume of countries' trade, the intensity of the Foreign Direct Investment (FDI) flows among the countries, the stability of their exchange rates, their inflation or interest rates, among others (Asgharian et al., 2013).

This paper is centered on studying the stock market dependence among the G7 countries, a group of countries whose stock markets should, at least theoretically, show significant co-movement. Despite the theoretical linkages among these countries, the empirical analysis will shed light on the time-varying dependence among the stock markets in these countries and the direction of the risk spillovers among stock markets. The choice of the G7 equity markets is quite natural given their importance in the global economy, with these countries representing nearly two-third of global net wealth, and nearly half of world output. Moreover, these markets are considered as matured markets, with them having been established long-time back. Naturally, this allows us to track the entire evolution of these markets, from its initial stage to the current level, by covering a century of data. Also note that, the decision to look at the spillover from the US on to the other developed markets of the G6 countries, is motivated by the fact that, the US stock returns is believed to have strong predictive power for equity markets of other developed economies (besides emerging markets). Detailed discussion in this regard can be found in Rapach et al., (2013) and Aye et al., 
(2017).

From an empirical point of view, the literature has used different definitions for and measurements of contagion. Many papers define contagion as a significant increase in the correlation coefficients between mean stock returns (Forbes and Rigobon, 2002; Bekaert et al., 2005; Boyer et al., 2006; Caporale et al., 2005; Bekaert et al., 2009; Jayasuriya, 2011; Ehrmann et al., 2011; Bekaert et al., 2014) or their volatilities (Bae et al., 2007; Diebold and Yilmaz, 2009; Beirne et al., 2010) in different markets during a crisis. In other words, they focus mainly on the first two moments of the distribution and ignore other moments. Additionally, according to most of these papers, stock markets tend to become closer during crises and periods of high volatility compared to financially stable times. In order to capture such nonlinearities in the data, regime switching models have also been used to test for contagion (Billio et al., 2005; Lopes and Nunes, 2012; Ang and Timmermann, 2011; Guo et al., 2011). However, again, the focus of these studies is on the first two moments of the distribution, disregarding other aspects, such as tail dependence, which seems to be a good measure of systemic risk (Adrian and Brunnermeier, 2011). Other papers in the literature have used quantile regression methodologies in order to capture this tail dependence or extreme risk (Longin and Solnik, 2001; Ang and Chen, 2002; Bae et al., 2003; Hong et al, 2007; Polanski and Stoja, 2015; Chuliá et al., 2017). Chuliá et al. (2017), for example, used multivariate quantile models to measure the tail dependence between the US and six Latin American countries, showing that this tail dependence is weaker than that between the US and more developed countries. Tail dependence has also been captured by Copula models (Reboredo and Ugolini, 2015; Reboredo et al., 2016). For example, Reboredo and Ugolini (2015) use copulas to analyse systemic risk in European sovereign debt markets and measure CoVaR. Based on above studies, we will 
extend Reboredo and Ugolini (2015)'s methodology and use time-varying copula models with Markov switching to estimate CoVaR as a proxy for systemic risk.

The objective of this paper is to analyse the risk spillover effect between the US stock market and the remaining G7 stock markets using time-varying copula models with Markov switching and a data that covers more than 100 years and numerous crises. This study makes at least three contributions to the literature. First, no paper to date has examined the risk spillover effect between the US stock market and the remaining G7 stock markets in a situation with extreme co-movement based on CoVaRs. Further, this study examines asymmetric risk spillover between upside and downside CoVaR and asymmetric risk spillover to and from the US stock market and the remaining G7 stock markets. Second, 100 years' worth of data is employed to investigate the evolution of risk spillover between the US and the remaining G7 stock markets. More information is involved in the data, and the influence of specific periods for landmark events can be identified. Furthermore, the use of over a century of data allows us to analyze a long period of time that includes different shocks, such as the Great Depression (1929-32), the World War II, the 1970s energy crisis, the early 1980s recession, the European sovereign debt crisis, or the Financial Crisis (2007-2009). Also note that, in the process of using the longest possible data span involving the equity markets of the G7, we are able to get around the sample selection bias, and hence avoid looking at only a specific stage of development of these equity markets. The long data samples allows us to obtain valid inferences by also involving large amount of data points, given that copula models are generally used for daily data, but with short sample spans. Finally, a more flexible time-varying copula model with Markov switching was developed for this long period of data to determine whether the dependence is high or low. Unlike previous studies that employ dynamic copulas 
(Reboredo and Ugolini, 2015; Reboredo et al., 2016; Mensi et al., 2017), this study uses a hidden two-state Markov chain of the intercept term when modelling the dynamic copula coefficient process, in line with Silva Filho et al. (2012). this methodology not only verifies the dynamics of risk spillover but also determines the structural change of dependencies.

The rest of the paper is organized as follows: Section 2 presents the methodology, while Section 3 discusses the data and the results. Section 4 presents the conclusion.

\section{Methodology}

In this paper, upside and downside CoVaRs are measured to quantify the risk spillover effects of extreme upward and downward changes in uncertainty from the US to the remaining six G7 stock markets. Time-varying copula models are employed to model the joint distribution and dynamic dependence between variables, similar to Reboredo and Ugolini (2015) and Mensi et al. (2017). However, unlike previous studies, we allow the dependence parameter to evolve over time and assume a hidden two-state Markov chain of the intercept term, similar to Silva Filho et al. (2012). Using this methodology, two distinct regimes (high dependence and low dependence) are defined in the emprical analysis. Liu et al. (2017) have presented the applicable conditions on various copulas. Generally, given the widely used copulas, the Normal copula or $t$ copula can describe both symmetric positive and negative dependence, but the Normal copula has no tail dependence and the $\mathrm{t}$ copula has symmetric tail dependence. Clayton, Rotated Clayton, Gumbel and Rotated Gumbel copulas can describe asymmetric positive dependence. Therefore, in this paper, the above six representative copulas have been employed using its time-varying modelling. 


\subsection{Markov-switching time-varying copula model}

\subsubsection{Main model}

For stock returns, $\boldsymbol{r}_{\boldsymbol{t}}=\left(r_{1, t}, r_{2, t}\right)$, given observations through time $t-1$, $\mathcal{F}_{t-1}$, the conditional joint distribution $F_{t}\left(x_{1}, x_{2} \mid \mathcal{F}_{t-1} ; \boldsymbol{\theta}\right)$, considering the unobserved regime variable, $s_{t}$, is as follows:

$$
F_{t}\left(x_{1}, x_{2} \mid \mathcal{F}_{t-1} ; \boldsymbol{\theta}\right)=\sum_{j=1}^{N} F_{t}\left(x_{1}, x_{2} \mid s_{t}=j, \mathcal{F}_{t-1} ; \boldsymbol{\theta}\right) \cdot \operatorname{Pr}\left(s_{t}=j \mid \mathcal{F}_{t-1}\right),
$$

where the regime $s_{t}$ at time $t$ evolves according to a Markov chain that is independent of past observations:

$$
\operatorname{Pr}\left(s_{t}=j \mid s_{t-1}=i, s_{t-2}=k, \cdots, \mathcal{F}_{t-1}\right)=\operatorname{Pr}\left(s_{t}=j \mid s_{t-1}=i\right)=p_{i j} .
$$

Consider a time-varying copula with the two-regime switching model (Silva Filho et al., 2012). Given $\mathcal{F}_{t-1}$ and $s_{t}$, the conditional joint distribution $F_{t}\left(x_{1}, x_{2} \mid s_{t}, \mathcal{F}_{t-1} ; \boldsymbol{\theta}\right)$ can be expressed as

$$
F_{t}\left(x_{1}, x_{2} \mid s_{t}, \mathcal{F}_{t-1} ; \boldsymbol{\theta}\right)=C_{t}\left(u_{1}, u_{2} \mid s_{t}, \mathcal{F}_{t-1} ; \boldsymbol{\theta}_{\boldsymbol{c}}\right)=C\left(u_{1}, u_{2} ; \kappa_{t, s_{t}}\right),
$$

and then the conditional joint distribution given $\mathcal{F}_{t-1}, F_{t}\left(x_{1}, x_{2} \mid \mathcal{F}_{t-1} ; \boldsymbol{\theta}\right)$, for the stock returns $\boldsymbol{r}_{\boldsymbol{t}}$ is

$F_{t}\left(x_{1}, x_{2} \mid \mathcal{F}_{t-1} ; \boldsymbol{\theta}\right)=\sum_{j=1}^{2} C_{t}\left(u_{1}, u_{2} \mid s_{t}=j, \mathcal{F}_{t-1} ; \boldsymbol{\theta}_{\boldsymbol{c}}\right) \cdot \operatorname{Pr}\left(s_{t}=j \mid \mathcal{F}_{t-1}\right)=C_{t}\left(u_{1}, u_{2} \mid \mathcal{F}_{t-1} ; \boldsymbol{\theta}_{\boldsymbol{c}}\right)(4)$

where $\boldsymbol{\theta}=\left(\boldsymbol{\theta}_{1}^{\prime}, \boldsymbol{\theta}_{2}^{\prime}, \boldsymbol{\theta}_{c}^{\prime}\right)^{\prime}, u_{i}=F_{i, t}\left(x_{i} \mid \mathcal{F}_{t-1} ; \boldsymbol{\theta}_{\boldsymbol{i}}\right), i=1,2$

The copula dependence parameter $\kappa_{t, s_{t}}$ evolves according to an ARMA-type process in which the intercept term of $\bar{\omega}_{s_{t}}$ depends on the regime $s_{t}$ shown in equation (5). Silva Filho et al. (2012) propose the Eq. (5), where it indicates that if the dependence regime at time $t$ is $s_{t}$, the dependence parameter $\kappa_{t, s_{t}}$ is the function of $\bar{\omega}_{s_{t}}$, i.e. intercept term at regime $s_{t}$, the dependence parameter $\kappa_{t-1}$ at time $t-1$ and the forcing variable $F V_{t}$. But in the procedures, they assume that dependence regime at time $t-1$ is equal to that at time $t$, that is, if the regime at time $t-1$ is low 
dependence regime, the regime at time $t$ must be low dependence for each dynamic process, and they employ two equations to describe the dynamic dependence. However, this assumption cannot fully match with the Eq. (5). To solve this point, we add a mean equation of $\kappa_{t, s_{t}}$ at time $t, \kappa_{t}=\sum_{j=1}^{2} \kappa_{t, s_{t}=j} \cdot \operatorname{Pr}\left(s_{t}=j \mid \mathcal{F}_{t}\right)$, given the information $\mathcal{F}_{t}$, and put it in the dynamic process of dependence parameter at each time point, and we can construct two parameters $\kappa_{t, s_{t}}$ at the following time point, then construct two conditional joint distribution given different regime $s_{t}$.

$$
\kappa_{t, s_{t}}=\Lambda\left(\bar{\omega}_{s_{t}}+\bar{\beta} \cdot \kappa_{t-1}+\bar{\alpha} \cdot F V_{t}\right) \text {, }
$$

where $\kappa_{t}$ is the weighted mean of $\kappa_{t, s_{t}}$ :

$$
\kappa_{t}=\sum_{j=1}^{2} \kappa_{t, s_{t}=j} \cdot \operatorname{Pr}\left(s_{t}=j \mid \mathcal{F}_{t}\right) .
$$

In Eq. (5), $F V_{t}$ is equal to $\frac{1}{m} \sum_{j=1}^{m} \phi^{-1}\left(u_{1, t-j}\right) \cdot \phi^{-1}\left(u_{2, t-j}\right)$ and $\frac{1}{m} \sum_{j=1}^{m} t_{n}^{-1}\left(u_{1, t-j}\right) \cdot t_{n}^{-1}\left(u_{2, t-\mathrm{j}}\right)$ for the Markov-switching time-varying normal (MSTVN) and $\mathrm{t}(\mathrm{MSTVt})$ copulas respectively, and $\frac{1}{m} \sum_{j=1}^{m}\left|u_{1, t-j}-u_{2, t-j}\right|$ for the Markov-switching time-varying Clayton (MSTVC), 180-degree rotated Clayton (MSTVRC), Gumbel (MSTVG) and 180-degree rotated Gumbel (MSTVRG) copulas (Patton, 2006).

Let $\quad \boldsymbol{\eta}_{\boldsymbol{t}}=\left(\begin{array}{c}c_{t}\left(u_{1, t}, u_{2, t} \mid s_{t}=1, \mathcal{F}_{t-1}\right) \\ c_{t}\left(u_{1, t}, u_{2, t} \mid s_{t}=2, \mathcal{F}_{t-1}\right)\end{array}\right) \quad, \quad \boldsymbol{\xi}_{\boldsymbol{t} \mid \boldsymbol{t}-\mathbf{1}}=\left(\begin{array}{c}\operatorname{Pr}\left(s_{t}=1 \mid \mathcal{F}_{t-1}\right) \\ \operatorname{Pr}\left(s_{t}=2 \mid \mathcal{F}_{t-1}\right)\end{array}\right) \quad$ and $\quad \boldsymbol{\xi}_{\boldsymbol{t} \mid \boldsymbol{t}}=$ $\left(\begin{array}{l}\operatorname{Pr}\left(s_{t}=1 \mid \mathcal{F}_{t}\right) \\ \operatorname{Pr}\left(s_{t}=2 \mid \mathcal{F}_{t}\right)\end{array}\right) \cdot u_{i, t}=F_{i, t}\left(r_{i, t} \mid \mathcal{F}_{t-1}\right), i=1,2$. Then, based on Eq. (4),

$$
f_{t}\left(r_{1, t}, r_{2, t} \mid \mathcal{F}_{t-1} ; \boldsymbol{\theta}\right)=\mathbf{1}^{\prime}\left(\xi_{\boldsymbol{t} \mid \boldsymbol{t}-\mathbf{1}} \odot \boldsymbol{\eta}_{\boldsymbol{t}}\right) \cdot \prod_{i=1}^{2} f_{i, t}\left(r_{i, t} \mid \mathcal{F}_{t-1} ; \boldsymbol{\theta}_{\boldsymbol{i}}\right)
$$

where $\mathbf{1}^{\prime}\left(\xi_{\boldsymbol{t} \mid \boldsymbol{t}-\mathbf{1}} \odot \boldsymbol{\eta}_{\boldsymbol{t}}\right)=c_{t}\left(\hat{u}_{1, t}, \hat{u}_{2, t} \mid \mathcal{F}_{t-1} ; \boldsymbol{\theta}_{\boldsymbol{c}}\right), \quad \boldsymbol{\xi}_{\boldsymbol{t}+\mathbf{1} \mid \boldsymbol{t}}=\boldsymbol{P} \boldsymbol{\xi}_{\boldsymbol{t} \mid \boldsymbol{t}}, \quad \boldsymbol{P}=\left(\begin{array}{ll}p_{11} & p_{21} \\ p_{12} & p_{22}\end{array}\right)$, $\xi_{t \mid \boldsymbol{t}}=\frac{\left(\begin{array}{c}\operatorname{Pr}\left(s_{t}=1 \mid \mathcal{F}_{t-1}\right) \\ \operatorname{Pr}\left(s_{t}=2 \mid \mathcal{F}_{t-1}\right)\end{array}\right) \odot\left(\begin{array}{c}f_{t}\left(r_{1, t}, r_{2, t} \mid s_{t}=1, \mathcal{F}\right. \\ f_{t-1}\left(r_{1, t}, r_{2, t} \mid s_{t}=2, \mathcal{F}_{t-1}\right)\end{array}\right)}{f_{t}\left(r_{1, t}, r_{2, t} \mid \mathcal{F}_{t-1}\right)}=\frac{\xi_{\boldsymbol{t} \mid t-1} \odot \boldsymbol{\eta}_{\boldsymbol{t}}}{\mathbf{1}^{\prime}\left(\xi_{t \mid t-1} \odot \boldsymbol{\eta}_{\boldsymbol{t}}\right)}$. Starting value $\boldsymbol{\xi}_{\mathbf{1} \mid \mathbf{0}}=\left(\begin{array}{c}0.5 \\ 0.5\end{array}\right)$ The sign $\odot$ denotes element-by-element multiplication. 
Let $\boldsymbol{\zeta}_{\boldsymbol{t} \mid \boldsymbol{T}}=\left(\begin{array}{c}\operatorname{Pr}\left(s_{t}=1 \mid \mathcal{F}_{T}\right) \\ \operatorname{Pr}\left(s_{t}=2 \mid \mathcal{F}_{T}\right)\end{array}\right)$ denote a smoothed inference about regime $s_{t}$ based on whole observations, which can be calculated using an algorithm developed by Kim (1994):

$$
\xi_{t \mid T}=\xi_{t \mid t} \odot\left(P^{\prime}\left(\xi_{t+1 \mid T} \div \xi_{t+1 \mid t}\right)\right), t<T
$$

where the sign $\div$ denotes element-by-element division. We calculate the smoothed probabilities $\xi_{t \mid T}$ by creating backward iterations of Eq. (8) for $t=T-1, T-$ $2, \cdots, 1$

\subsubsection{Marginal distribution}

Since financial market returns are always characterised by autocorrelation and volatility clustering, following most of previous literature (Liu et al., 2017; Ji et al., 2018a, b, c), we employ an $\operatorname{ARMA}(m, n)-\operatorname{GARCH}(p, q)-t$ model to construct the conditional marginal distributions ${ }^{1}$ :

$$
\begin{gathered}
r_{i, t}=\varphi_{0}+\sum_{j=1}^{m} \varphi_{j} r_{i, t-j}+\varepsilon_{i, t}+\sum_{j=1}^{n} \psi_{j} \varepsilon_{i, t-j}=\mu_{i, t}+\varepsilon_{i, t}, i=1,2, \\
\varepsilon_{i, t}=\sigma_{i, t} z_{i, t}, z_{i, t} \sim \text { i.i.d. } t_{v_{i}} \text { and } \\
\sigma_{i, t}^{2}=\alpha_{0}+\sum_{j=1}^{p} \alpha_{j} \varepsilon_{i, t-j}^{2}+\sum_{j=1}^{p} \beta_{j} \sigma_{i, t-j}^{2},
\end{gathered}
$$

where $\mu_{i, t}=E\left(r_{i, t} \mid \mathcal{F}_{t-1}\right)$ and $\sigma_{i, t}^{2}=\operatorname{Var}\left(r_{i, t} \mid \mathcal{F}_{t-1}\right)$.

By distributing the standardised residual, $t_{v_{i}}$, we can obtain the conditional distribution of returns, $r_{i, t}$ :

$F_{i, t}\left(x_{i} \mid \mathcal{F}_{t-1} ; \boldsymbol{\theta}_{\boldsymbol{i}}\right)=\operatorname{Pr}\left(r_{i, t} \leq x_{i} \mid \mathcal{F}_{t-1}\right)=\operatorname{Pr}\left(\frac{r_{i, t}-\mu_{i, t}}{\sigma_{i, t}} \leq \frac{x_{i}-\mu_{i, t}}{\sigma_{i, t}} \mid \mathcal{F}_{t-1}\right)=t_{v_{i}}\left(\frac{x_{i}-\mu_{i, t}}{\sigma_{i, t}} \mid \mathcal{F}_{t-1}\right)$

\subsubsection{Estimation}

We employ the inference for margins (IFM) method proposed by Joe and $\mathrm{Xu}$ (1996) to estimate the parameter $\boldsymbol{\theta}=\left(\boldsymbol{\theta}_{1}^{\prime}, \boldsymbol{\theta}_{2}^{\prime}, \boldsymbol{\theta}_{c}^{\prime}\right)^{\prime}$ as follows:

\footnotetext{
${ }^{1}$ In this paper, we ignore to test the potential structural change in the marginal models, because of its complexity combing with time-varying copula models. We hope to find a feasible way to solve this problem in the future research.
} 
Step 1: Estimate the conditional marginal distribution parameter $\boldsymbol{\theta}_{\boldsymbol{i}}$ :

$$
\widehat{\boldsymbol{\theta}}_{\boldsymbol{i}}=\underset{\boldsymbol{\theta}_{\boldsymbol{i}}}{\operatorname{argmax}} \sum_{t=1}^{T} \log \left(f_{i, t}\left(r_{i, t} \mid \mathcal{F}_{t-1} ; \boldsymbol{\theta}_{\boldsymbol{i}}\right)\right), i=1,2
$$

Step 2: Estimate the conditional copula parameter, $\boldsymbol{\theta}_{\boldsymbol{c}}$ :

$$
\widehat{\boldsymbol{\theta}}_{\boldsymbol{c}}=\underset{\boldsymbol{\theta}_{\boldsymbol{c}}}{\operatorname{argmax}} \sum_{t=1}^{T} \log \left(c_{t}\left(\hat{u}_{1, t}, \hat{u}_{2, t} \mid \mathcal{F}_{t-1} ; \boldsymbol{\theta}_{\boldsymbol{c}}\right)\right) \text {. }
$$

Joe (1997) proves that the IFM estimator $\widehat{\boldsymbol{\theta}}=\left(\widehat{\boldsymbol{\theta}}_{1}^{\prime}, \widehat{\boldsymbol{\theta}}_{2}^{\prime}, \widehat{\boldsymbol{\theta}}_{\boldsymbol{c}}^{\prime}\right)^{\prime}$ verifies the property of asymptotic normality under regular conditions:

$$
\sqrt{T}(\widehat{\boldsymbol{\theta}}-\boldsymbol{\theta}) \rightarrow N\left(\mathbf{0}, G^{-1}(\boldsymbol{\theta})\right)
$$

where $G(\boldsymbol{\theta})$ is a Godambe information matrix.

\subsection{Risk spillover modelling}

In this paper, we employ tail dependence and CoVaR to identify risk spillover across stock markets.

For the copula at time $t$ presented in Eq. (4), we employ lower and upper tail dependence to measure extreme co-movement across markets (Joe, 1997; Liu et al., 2017).

For two small real numbers, $\alpha$ and $\beta$ (e.g. $\alpha=\beta=0.05$ ), the two dynamic tail dependences are as follows:

$$
\begin{gathered}
\tau_{t}^{L L}(\alpha, \beta)=\operatorname{Pr}\left(F_{1, t}\left(r_{1, t} \mid \mathcal{F}_{t-1}\right)<\alpha \mid F_{2, t}\left(r_{2, t} \mid \mathcal{F}_{t-1}\right)<\beta\right)=\frac{C_{t}\left(\alpha, \beta \mid \mathcal{F}_{t-1}\right)}{\beta} \\
\tau_{t}^{U U}(\alpha, \beta)=\operatorname{Pr}\left(F_{1, t}\left(r_{1, t} \mid \mathcal{F}_{t-1}\right)>1-\alpha \mid F_{2, t}\left(r_{2, t} \mid \mathcal{F}_{t-1}\right)>1-\beta\right)=\frac{C_{t}\left(1-\alpha, 1-\beta \mid \mathcal{F}_{t-1}\right)+\alpha+\beta-1}{\beta}(1)
\end{gathered}
$$

We employ CoVaR to measure risk spillover across markets (Reboredo and Ugolini, 2015; Reboredo et al., 2016):

$$
\begin{aligned}
& \operatorname{Pr}\left(r_{1, t} \leq \operatorname{CoVaR}_{1 \mid 2 D, t}^{D, \alpha} \mid r_{2, t} \leq \operatorname{VaR}_{2, t}^{D, \beta}\right)=\alpha \\
& \operatorname{Pr}\left(r_{1, t} \geq \operatorname{CoVaR}_{1 \mid 2 U, t}^{U, \alpha} \mid r_{2, t} \geq \operatorname{VaR}_{2, t}^{U, \beta}\right)=\alpha,
\end{aligned}
$$

where $\operatorname{Pr}\left(r_{2, t} \leq \operatorname{VaR} R_{2, t}^{D, \beta}\right)=\beta \quad$ and $\operatorname{Pr}\left(r_{2, t} \geq \operatorname{VaR} R_{2, t}^{U, \beta}\right)=\beta . \operatorname{CoVaR}_{1 \mid 2 D, t}^{D, \alpha}$ and 
$\operatorname{CoVaR}_{1 \mid 2 U, t}^{U, \alpha}$ can be obtained by solving the following two equations:

$$
\begin{gathered}
C_{t}\left(F_{1, t}\left(\operatorname{CoVaR}_{1 \mid 2 D, t}^{D, \alpha} \mid \mathcal{F}_{t-1}\right), \beta \mid \mathcal{F}_{t-1}\right)-\beta \alpha=0 \\
F_{1, t}\left(\operatorname{CoVaR}_{1 \mid 2 U, t}^{U, \alpha} \mid \mathcal{F}_{t-1}\right)-C_{t}\left(F_{1, t}\left(\operatorname{CoVaR}_{1 \mid 2 U, t}^{U, \alpha} \mid \mathcal{F}_{t-1}\right), 1-\beta \mid \mathcal{F}_{t-1}\right)-\beta+\beta \alpha=0
\end{gathered}
$$

\section{Empirical results}

\subsection{Data and summary statistics}

This study analyses over one hundred years' worth of data regarding the stock markets of G7 countries - the US (USA), Canada (CAN), France (FRA), Germany (GER), Japan (JPN), Italy (ITA) and the United Kingdom (UK) - to measure extreme risk spillover. The sample period ranges from January 1915 to February $2017^{2}$, and the monthly frequency is 1,111 observations for each series. All data are obtained from the Global Financial Database. We use the differences of the natural logarithm of stock prices to determine the return series.

Table 1 presents the summary statistics for G7 countries' stock returns. Panel A shows that the means of all countries' stock returns are positive, indicating that the stock markets showed a general upward trend over a long period of time. JPN has the largest mean (0.616), and CAN has the smallest (0.427). There is no significant difference in the minimum returns for most countries, but GER has a significantly lower minimum return than the others (-145.996). This slump took place in July 1948 due to World War II. USA is more stable than the other countries and has the smallest standard deviation (4.459), while ITA is the most volatile and has the largest standard deviation (7.239), followed by GER (6.771). The skewness and kurtosis of the statistics indicate that all returns have asymmetric leptokurtic characteristics, and the

\footnotetext{
2 The original data sample was collected from January 1915 to February 2017, but there are many monthly zero return data regarding the French stock market from 1915 to 1924 . Therefore, to avoid bias estimation due to data quality, data from July 1924 to February 2017 is eliminated from coefficient estimations.
} 
Jarque-Bera statistics significantly reject the null hypothesis of normal distribution for all returns. Panel B presents the correlations among stock returns, all of which are significantly positive at the $1 \%$ level. The correlation coefficient between CAN and USA is highest (0.702), and the other correlation coefficients are around 0.3. These significant correlations indicate the integration of developed countries' stock markets, which allows for information shocks and risk spillover across countries.

Figure 1 presents the Granger causal flows among G7 stock returns, showing that there are close lagged relationships among these countries' stock markets. Interestingly, USA is the most influenced market in the Granger causality network. All G7 countries' stock returns — except those of JPN—can lead to Granger causal stock returns for USA at the 5\% significance level. In addition, USA can also lead to Granger causal returns for UK and CAN at the 5\% significance level. FRA is the only country with only outflows of Granger causality, while JPN is the only one with only inflows of Granger causality.

Table 1. Summary statistics

\begin{tabular}{|c|c|c|c|c|c|c|c|c|}
\hline \multicolumn{9}{|c|}{ Panel A: data statistics } \\
\hline & Mean & Median & Max. & Min. & Std. Dev. & Skew. & Kurt. & Jarque-Bera \\
\hline CAN & 0.427 & 0.770 & 20.589 & -33.460 & 4.688 & -1.063 & 8.496 & $1607.539 * * a$ \\
\hline FRA & 0.607 & 0.732 & 24.255 & -27.605 & 5.563 & -0.136 & 4.304 & $82.214 * *$ \\
\hline GER & 0.447 & 0.377 & 38.238 & -145.996 & 6.771 & -9.037 & 200.238 & $1.8 \mathrm{E}+6^{* *}$ \\
\hline JPN & 0.616 & 0.626 & 50.872 & -27.216 & 6.120 & 0.589 & 10.081 & $2384.955^{* *}$ \\
\hline ITA & 0.570 & 0.322 & 46.811 & -30.757 & 7.239 & 0.901 & 8.480 & $1540.299 * *$ \\
\hline UK & 0.443 & 0.828 & 42.320 & -30.924 & 4.723 & -0.151 & 11.936 & $3700.945 * *$ \\
\hline USA & 0.501 & 0.971 & 40.746 & -30.753 & 4.459 & -0.509 & 15.070 & $6792.302 * *$ \\
\hline \multicolumn{9}{|c|}{ Panel B: correlation coefficients } \\
\hline \multicolumn{3}{|c|}{ CAN } & FRA & GER & JPN & ITA & UK & USA \\
\hline CAN & & L & & & & & & \\
\hline FRA & & $2 * *$ & 1 & & & & & \\
\hline GER & & $7 * *$ & $0.313 * *$ & 1 & & & & \\
\hline JPN & & $7 * *$ & $0.224 * *$ & $0.135^{* *}$ & 1 & & & \\
\hline ITA & & $8 * *$ & $0.358^{* *}$ & $0.268^{* *}$ & $0.224 * *$ & 1 & & \\
\hline UK & & $7 * *$ & $0.422 * *$ & $0.297 * *$ & $0.222 * *$ & $0.338^{* *}$ & 1 & \\
\hline USA & & $2 * *$ & $0.338 * *$ & $0.277 * *$ & $0.164 * *$ & $0.289 * *$ & $0.393 * *$ & 1 \\
\hline
\end{tabular}


Note: ${ }^{\text {a } *}$ denotes significant at the $1 \%$ level.

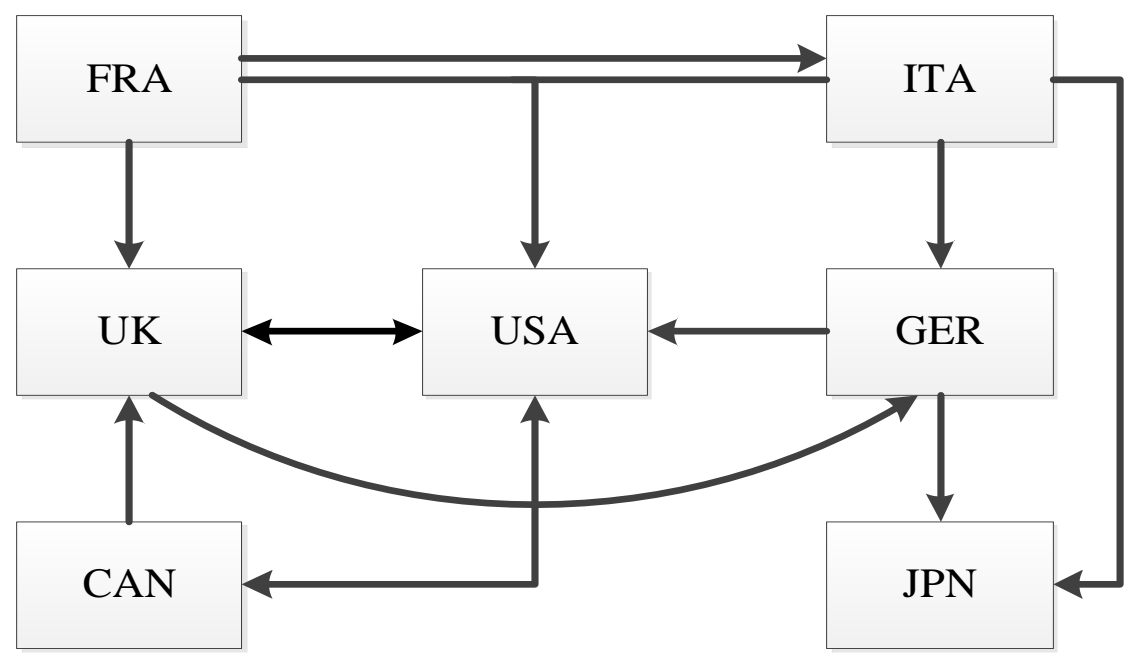

Figure 1. Granger causality among G7 stock returns

(Note: An arrow denotes Granger causality at a 5\% significance level)

\subsection{Model estimation}

Before estimating the marginal distribution of stock returns, some necessary diagnoses need to be tested. Table 2 presents the autocorrelation and conditional heteroscedasticity tests for the G7 stock returns. The Ljung-Box test results, represented by $Q_{r}$, indicate that the stock returns feature significant autocorrelation. When ARMA models are used to estimate stock returns, the autocorrelation (measured by $Q_{a}$ ) disappears, and significant $\mathrm{ARCH}$ effects are measured by $Q_{a}^{2}$ and the Lagrange Multiplier test, the results of which are represented by $L_{a}$. Furthermore, where an ARMA-GARCH process is applied to stock returns, it is revealed that the null hypothesis (no autocorrelation and conditional heteroscedasticity) cannot be rejected, except in the case of GER. Therefore, it is reasonable to use ARMA-GARCH models to estimate the marginal distribution of G7 stock returns. GER's stock returns do not show evidence of conditional heteroscedasticity, which indicates that its market risk stays almost constant over time. Therefore, GER is not considered in our further investigation of risk spillover. 
Table 2. Autocorrelation and conditional heteroscedasticity tests

\begin{tabular}{cccccccc}
\hline \hline & $\boldsymbol{Q}_{\boldsymbol{r}}(\mathbf{8})^{\mathrm{b}}$ & $\boldsymbol{Q}_{\boldsymbol{a}}(\mathbf{8})$ & $\boldsymbol{Q}_{\boldsymbol{a}}^{\mathbf{2}}(\mathbf{8})$ & $\boldsymbol{L}_{\boldsymbol{a}}(\mathbf{8})^{\mathrm{c}}$ & $\boldsymbol{Q}_{\boldsymbol{\varepsilon}}(\mathbf{8})^{\mathrm{d}}$ & $\boldsymbol{Q}_{\boldsymbol{\varepsilon}}^{\mathbf{2}}(\mathbf{8})$ & $\boldsymbol{L}_{\boldsymbol{\varepsilon}}(\mathbf{8})$ \\
\hline CAN & $44.323 * * \mathrm{a}$ & 7.670 & $86.364 * *$ & $58.945 * *$ & 5.977 & 2.163 & 2.252 \\
$\mathbf{F R A}$ & $29.693 * *$ & 8.469 & $78.680 * *$ & $50.848 * *$ & 8.032 & 3.630 & 3.537 \\
$\mathbf{G E R}$ & $32.374 * *$ & 5.928 & 0.096 & 0.090 & -- & -- & -- \\
JPN & $19.213^{*}$ & 8.394 & $324.969 * *$ & $172.158 * *$ & 5.872 & 3.979 & 3.948 \\
$\mathbf{I T A}$ & $47.881^{* *}$ & 13.627 & $210.799 * *$ & $113.325 * *$ & 12.542 & 8.612 & 8.365 \\
UK & $26.972 * *$ & 12.323 & $114.388 * *$ & $69.650 * *$ & 7.542 & 4.686 & 4.989 \\
USA & $103.853^{* *}$ & 10.512 & $244.799 * *$ & $157.932 * *$ & 9.221 & 6.048 & 6.063 \\
\hline \hline
\end{tabular}

Note: ${ }^{\text {a }}$ and $* *$ denote significance levels of $5 \%$ and $1 \%$, respectively.

${ }^{\mathrm{b}} \mathrm{Q}$ and $\mathrm{Q} 2$ denote the Ljung-Box statistics for corresponding series and squared series, respectively.

${ }^{c}$ LM denotes the Lagrange Multiplier test statistic for conditional heteroscedasticity.

${ }^{\mathrm{d}} Q_{r}$ denotes $\mathrm{Q}$ statistics for stock returns, $Q_{a}$ denotes $\mathrm{Q}$ statistics for ARMA process and $Q_{\varepsilon}$ denotes $\mathrm{Q}$ statistics for ARMA-GARCH process.

Table 3 presents the estimated coefficients of marginal distribution for each stock return based on the $\operatorname{ARMA}(m, n)-\operatorname{GARCH}(p, q)-t$ model. The optimal lagged order of the $\operatorname{ARMA}(\mathrm{m}, \mathrm{n})-\mathrm{GARCH}(\mathrm{p}, \mathrm{q})-\mathrm{t}$ model is determined by the BIC information criterion. From table 3, following Patton (2013) and Ji et al. (2018), we employ the KS and CvM statistics for good-of-fit test. The results show that all conditional marginal distributions are not rejected at 1\% level, indicating that all marginal distributions are reasonable. Meanwhile, table 3 shows that there are some differences in the estimated models for each series. JPN follows the $\operatorname{AR}(1)-\operatorname{GARCH}(1,1)$ process and UK follows the $\operatorname{ARMA}(1,1)-\operatorname{GARCH}(1,1)$ process, while other series follow the MA(1)-GARCH(1, 1) process. All the standardised residuals feature a t distribution. The degree of freedom of the $t$ distribution, measured by $v$, is less than 10 , indicating that the error terms were not normal. This result is consistent with the evidence presented in Table 1. 
Table 3. Coefficient estimation of marginal distribution for each stock return

\begin{tabular}{ccccccc}
\hline \hline & \multicolumn{1}{c}{ CAN } & FRA & JPN & ITA & UK & USA \\
\hline \multicolumn{2}{c}{ Conditional mean } & & & & & \\
$\boldsymbol{\varphi}_{\mathbf{0}}$ & $0.796(0.126)^{a}$ & $0.633(0.172)$ & $0.499(0.125)$ & $0.437(0.185)$ & $0.803(0.294)$ & $0.939(0.115)$ \\
$\boldsymbol{\varphi}_{\mathbf{1}}$ & & $0.101(0.031)$ & & $-0.180(0.395)$ & \\
$\boldsymbol{\psi}_{\mathbf{1}}$ & $0.138(0.030)$ & $0.169(0.031)$ & & $0.163(0.031)$ & $0.254(0.388)$ & $0.239(0.029)$ \\
Conditional variance & & & & & \\
\\
$\boldsymbol{\alpha}_{\mathbf{0}}$ & $1.258(0.475)$ & $1.849(0.772)$ & $0.686(0.288)$ & $1.408(0.529)$ & $0.518(0.201)$ & $0.778(0.269)$ \\
$\boldsymbol{\alpha}_{\mathbf{1}}$ & $0.108(0.029)$ & $0.101(0.026)$ & $0.152(0.030)$ & $0.132(0.028)$ & $0.189(0.036)$ & $0.093(0.024)$ \\
$\boldsymbol{\beta}_{\mathbf{1}}$ & $0.835(0.041)$ & $0.841(0.042)$ & $0.843(0.028)$ & $0.843(0.029)$ & $0.811(0.030)$ & $0.860(0.032)$ \\
$\mathbf{v}$ & $5.107(0.756)$ & $9.903(2.408)$ & $5.649(0.943)$ & $6.763(1.376)$ & $5.794(0.977)$ & $4.436(0.656)$ \\
Goodness-of-fit tests (1000 times) & & & & \\
KS & 0.279 & 0.283 & 0.603 & 0.681 & 0.650 & 0.036 \\
CvM & 0.208 & 0.366 & 0.479 & 0.583 & 0.656 & 0.045 \\
\hline \hline
\end{tabular}

We use six time-varying copulas with regime-switching models to calculate the dependence of each pair of stock returns. Table 4 presents the log-likelihood values for the six selected time-varying copulas with regime switching, including MSTVN, MSTVt, MSTVC, MSTVRC, MSTVG and MSTVRG copulas, and also the log-likelihood values for the corresponding static copulas, i.e. N, t, C, RC, G and RG copulas. We can find that all log-likelihood values for the time-varying copulas with regime switching are obviously larger than those for the corresponding static copulas for all asset pairs, indicating that it is valuable to employ time-varying copulas with regime switching to explore the dependence and measure the CoVaR between financial assets. Thus, this paper prefers the time-varying copulas with regime switching to static copulas for the empirical analysis. As presented in table 4, MSTVt is optimal for CAN-USA, JPN-USA and UK-USA analyses, MSTVN is optimal for ITA-USA analyses, while MSTCRG is optimal for FRA-USA analyses according to the log-likelihood values of all time-varying copulas with regime switching. The dependence of the whole sample for each pair of stock returns is also calculated and shown in Table 4. The static dependence of CAN-USA is highest, and there is no significant difference between the other four pairs, consistent with the correlation results presented in Table 1 . 
Table 4. The log-likelihood value for time-varying copula with regime switching

\begin{tabular}{cccccc}
\hline \hline & CAN-USA & FRA-USA & JPN-USA & ITA-USA & UK-USA \\
\hline Kendall $^{\text {a }}$ & 0.444 & 0.190 & 0.118 & 0.185 & 0.236 \\
\hline MSTVN & 334.414 & 76.448 & 45.429 & $\mathbf{7 5 . 3 0 9}$ b & 105.829 \\
MSTVt & $\mathbf{3 4 2 . 3 7 0}$ & 78.263 & $\mathbf{4 6 . 0 0 1}$ & 73.865 & $\mathbf{1 1 0 . 3 8 3}$ \\
MSTVC & 298.749 & 77.199 & 45.277 & 65.095 & 102.810 \\
MSTVRC & 236.425 & 45.223 & 27.094 & 53.999 & 63.387 \\
MSTVG & 309.165 & 63.653 & 37.463 & 67.016 & 90.533 \\
MSTVRG & 327.789 & $\mathbf{7 8 . 5 1 2}$ & 45.307 & 70.702 & 104.697 \\
\hline N & 303.663 & 60.506 & 19.189 & 53.435 & 91.745 \\
t & 318.774 & 65.310 & 25.426 & 58.430 & 98.248 \\
C & 266.755 & 69.348 & 22.183 & 55.995 & 92.158 \\
RC & 222.063 & 29.070 & 10.282 & 30.741 & 55.389 \\
G & 289.182 & 48.021 & 16.824 & 44.837 & 78.860 \\
RG & 302.339 & 70.311 & 22.352 & 60.379 & 94.233 \\
\hline \hline
\end{tabular}

Note: ${ }^{a}$ Kendall denotes the Kendall coefficient over the whole sample period.

${ }^{\mathrm{b}}$ Bold denotes the maximum log-likelihood value.

Table 5 presents the estimated coefficients with the optimal Markov-switching time-varying copula models for each pair, as determined by Table 4 . In this paper, we employ IFM method to estimate the copula model according to Joe (1997), where the standard errors should be computed via Godambe matrix and have uniqueness if the scores vector and hessian matrix are obtained. The corresponding standard errors indicate that most parameters are significantly different from 0 . In this section, we differentiate the two regimes modelled in Eq. (5) as high dependence and low dependence regimes. Table 5 presents the estimated probabilities of $p_{11}$ and $p_{22}$, both of which are significantly close to 1 , indicating persistence of a high or low dependence regime. $\omega_{1}$ and $\omega_{2}$ are identified as the intercept terms of the two regimes, respectively. The substantial difference between $\omega_{1}$ and $\omega_{2}$ verifies the change between high and low dependence, with $\omega_{1}$ denoting high dependence and $\omega_{2}$ denoting low dependence. In this study, high dependence refers to excess co-movement over a normal degree between assets in two countries usually induced by an external shock, such as a financial crisis. Low dependence means that 
co-movement between assets in two countries remains at a normal level in a tranquil market environment.

Table 5. Coefficient estimation for time-varying copula with regime switching

\begin{tabular}{cccccccc}
\hline \hline & $\boldsymbol{\omega}_{\mathbf{1}}$ & $\boldsymbol{\omega}_{\mathbf{2}}$ & $\boldsymbol{\beta}$ & $\boldsymbol{\alpha}$ & $\boldsymbol{n}$ & $\boldsymbol{p}_{\mathbf{1 1}}$ & $\boldsymbol{p}_{\mathbf{2 2}}$ \\
\hline \multirow{2}{*}{ CAN-USA } & 1.847 & 1.047 & 0.251 & 0.049 & 8.028 & 0.998 & 1.000 \\
& $(0.371)^{\mathrm{a}}$ & $(0.269)$ & $(0.565)$ & $(0.113)$ & $(2.079)$ & $(0.002)$ & $(0.005)$ \\
FRA-USA & -0.114 & -0.385 & 0.508 & 0.105 & & 0.996 & 0.987 \\
& $(0.335)$ & $(0.262)$ & $(0.278)$ & $(0.270)$ & - & $(0.003)$ & $(0.008)$ \\
JPN-USA & 1.888 & 0.312 & -1.941 & 0.527 & 20.413 & 0.995 & 0.997 \\
& $(0.483)$ & $(0.199)$ & $(0.097)$ & $(0.258)$ & $(14.553)$ & $(0.004)$ & $(0.002)$ \\
ITA-USA & 2.527 & 0.801 & -2.049 & 0.242 & & 0.987 & 0.996 \\
& $(0.298)$ & $(0.139)$ & $(0.053)$ & $(0.232)$ & -- & $(0.011)$ & $(0.002)$ \\
UK-USA & 2.747 & 1.239 & -2.034 & 0.069 & 12.303 & 0.993 & 0.999 \\
& $(0.215)$ & $(0.154)$ & $(0.086)$ & $(0.140)$ & $(4.707)$ & $(0.004)$ & $(0.000)$ \\
\hline \hline
\end{tabular}

Note: ${ }^{a}$ () denotes the standard error.

\subsection{Smoothed probabilities and tail dependences}

The two dependence regimes defined above can also be verified by smoothed probabilities and tail dependences. Figure 2 presents the time-varying smoothed probabilities of high and low dependence for each stock return pair. At each time point, the sum of the probabilities of high dependence and low dependence is equal to 1, but the probability of switching between high and low dependence for each pair differs over time. For CAN-USA, the smoothed probability is significantly divided into two intervals, with the dependence relation remaining high before 1960 and becoming low after 1970. During the period from 1960 to 1970 , the dependence relation is in transition. The dependence relations for JPN-USA, ITA-USA and UKUSA are relatively stable, continuously remaining at a high or low dependence regime. Figure 2 shows that these dependence relationships tend to remain low before 2000, and they remain at a high dependence regime in the 21 st century. This means that the global economic integration and a more open market environment have led to closer relationships between markets. The transformation of smoothed probabilities for 
FRA-USA is specific and relatively unstable. However, although the smoothed probabilities of FRA-USA frequently transitioned between high and low dependence, a high dependence regime remained dominant after 2000 .
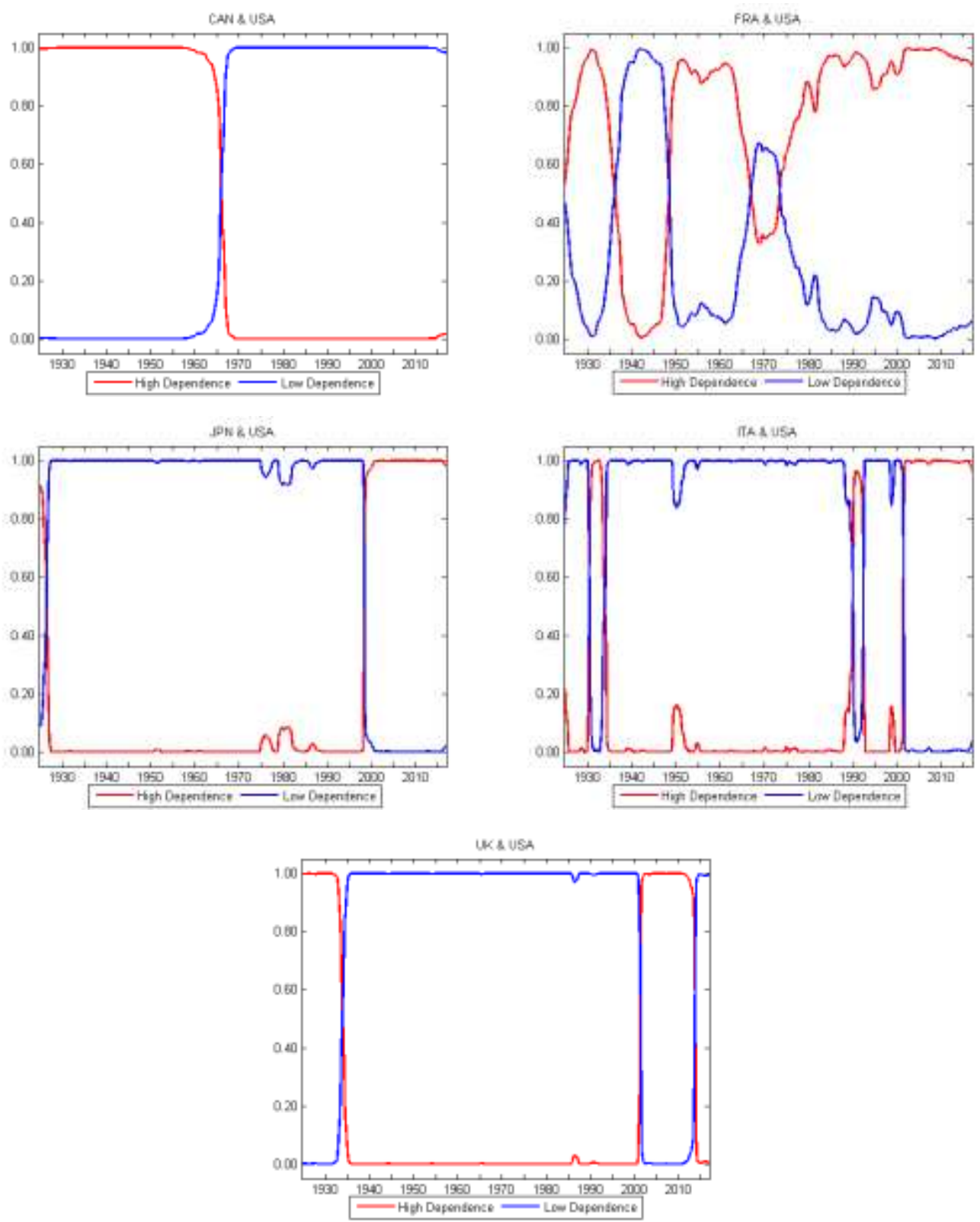

Figure 2. Smoothed probabilities for low and high dependence regimes

The lower and upper tail dependences between the US and the remaining G7 stock returns are presented in Figure $3^{3}$. Similar tail dependence behaviour was found

\footnotetext{
3 The lower and upper tail dependences are the same for all pairs except FRA-USA due to the symmetric copula function.
} 
for the smoothed probabilities for each pair. Correspondingly, the tail dependence parameters are lower during low dependence regimes, and they are higher during high dependence regimes. In the same dependence regime, the tail dependence is volatile, indicating the dynamic dependence structure of asset pairs between the US and remaining G7 stock returns.
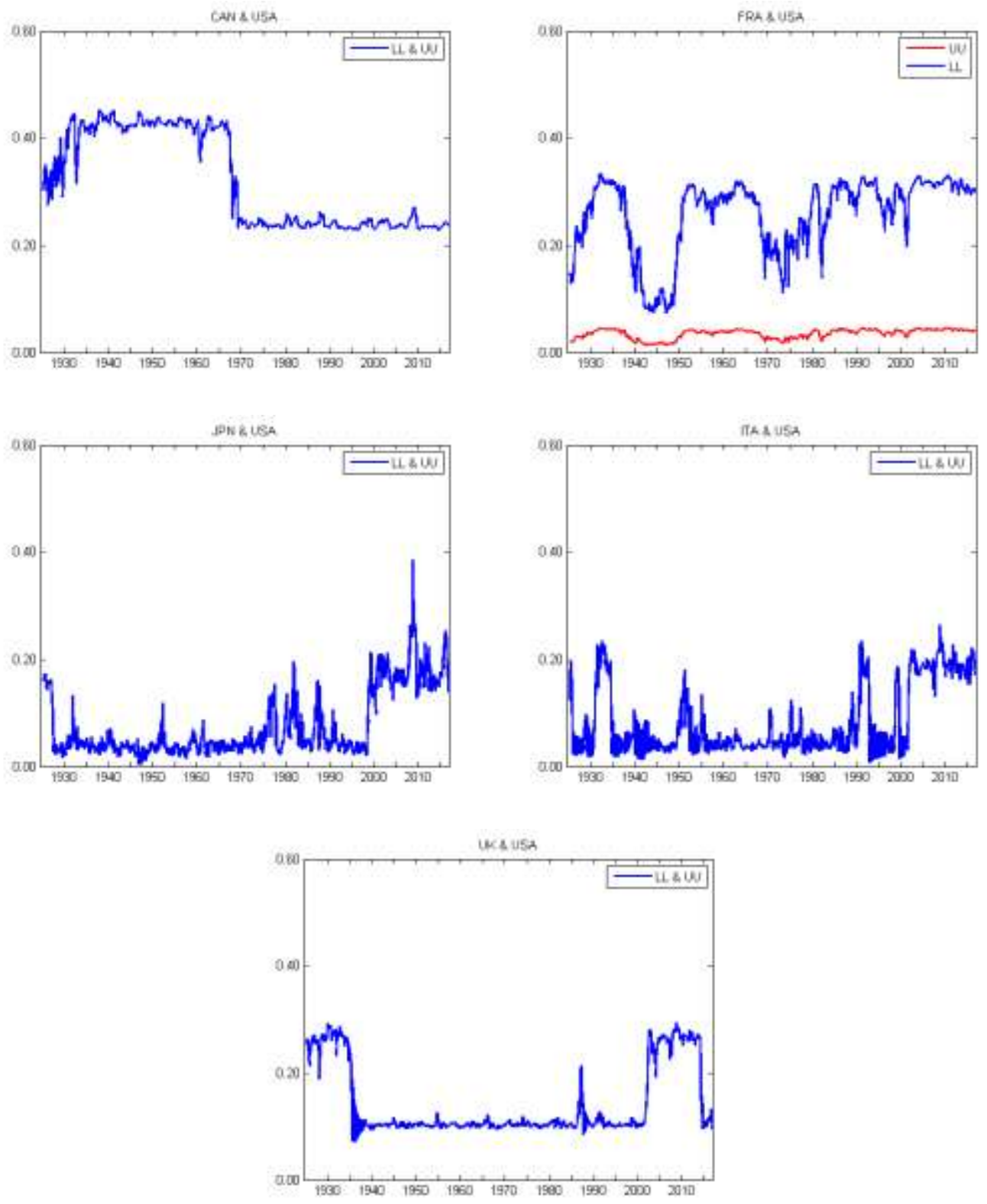

Figure 3. Lower and upper tail dependences between the US and the other G7 stock returns 


\subsection{Spillover from the US to the remaining G7 stock returns}

The findings presented above have verified the dynamic dependences between the US and the remaining G7 stock returns and have identified the dependence regimes in different periods. Furthermore, to investigate the spillover from the US to the rest of the G7 stock returns, the upside and downside VaRs and CoVaRs for G7 stock returns are estimated based on our optimal regime-switching time-varying copulas. In this section, CoVaR is measured as the VaR for G7 stock returns at a 95\% confidence level $(\beta=0.05)$ conditional on the VaR for the US stock return at the $95 \%$ confidence level $(\alpha=0.05)$. CoVaR is used to measure the impact of extreme risk in the US stock market on the risk level in the remaining G7 stock markets, which is a good indicator of risk spillover. Table 6 presents the summary statistics of VaRs and CoVaRs. In Panel A of Table 6, the upside and downside VaRs for the US stock returns are calculated. Comparison of the value of VaRs for the US market with the value of the VaRs for the other G7 markets, as shown in Panels B-F in Table 6, the absolute mean VaR for the US is smallest regardless of whether the VaR was upside or downside, indicating that the US is safer than the other G7 countries in the financial market. However, there are not significant differences among the standard deviations of the VaRs of the G7 countries. The upside and downside CoVaRs for the G7 countries are also calculated and shown in Panels B-F of Table 6. The results indicate that the CoVaR values are almost twice as large as their corresponding VaR values. The mean CoVaR for Italy is highest of all the G7 countries, consistent with the ranking of its VaR. 
Table 6. Summary statistics for VaRs and CoVaRs

\begin{tabular}{|c|c|c|c|c|c|}
\hline & Mean & Median & Max. & Min. & Std. Dev. \\
\hline \multicolumn{6}{|l|}{ Panel A } \\
\hline$V a R_{U S A}^{D}$ & -5.208 & -4.478 & -2.601 & -24.084 & 2.609 \\
\hline$V a R_{U S A}^{U}$ & 6.918 & 6.280 & 33.192 & 4.362 & 2.395 \\
\hline \multicolumn{6}{|l|}{ Panel B } \\
\hline$V a R_{C A N}^{D}$ & -6.227 & -5.548 & -3.797 & -23.770 & 2.243 \\
\hline $\operatorname{VaR}_{C A N}^{U}$ & 7.729 & 7.064 & 21.099 & 5.485 & 2.040 \\
\hline $\operatorname{CoVaR}_{C A N \mid U S A(D)}^{D}$ & -14.402 & -12.986 & -9.093 & -48.193 & 4.708 \\
\hline $\operatorname{CoVaR}_{C A N \mid U S A(U)}^{U}$ & 15.904 & 14.516 & 42.686 & 10.759 & 4.493 \\
\hline \multicolumn{6}{|l|}{ Panel C } \\
\hline $\operatorname{VaR}_{F R A}^{D}$ & -8.186 & -7.715 & -4.971 & -20.026 & 2.028 \\
\hline $\operatorname{VaR}_{F R A}^{U}$ & 9.444 & 8.959 & 20.810 & 6.406 & 2.046 \\
\hline $\operatorname{CoVaR} R_{F R A \mid U S A(D)}^{D}$ & -14.876 & -14.276 & -9.524 & -33.802 & 3.258 \\
\hline $\operatorname{CoVaR}_{F R A \mid U S A(U)}^{U}$ & 11.952 & 11.369 & 26.624 & 7.842 & 2.457 \\
\hline \multicolumn{6}{|l|}{ Panel D } \\
\hline$V a R_{J P N}^{D}$ & -8.476 & -7.593 & -3.340 & -35.362 & 4.409 \\
\hline$V a R_{J P N}^{U}$ & 9.598 & 8.756 & 43.330 & 4.384 & 4.495 \\
\hline $\operatorname{CoVaR}_{J P N \mid U S A(D)}^{D}$ & -12.411 & -10.966 & -4.302 & -46.335 & 6.235 \\
\hline $\operatorname{CoVaR} R_{J P N \mid U S A(U)}^{U}$ & 13.533 & 12.165 & 48.213 & 5.366 & 6.261 \\
\hline \multicolumn{6}{|l|}{ Panel E } \\
\hline$V a R_{I T A}^{D}$ & -10.162 & -9.137 & -5.010 & -32.887 & 4.447 \\
\hline$V a R_{I T A}^{U}$ & 11.073 & 9.920 & 41.471 & 5.796 & 4.654 \\
\hline $\operatorname{CoVaR} R_{I T A \mid U S A(D)}^{D}$ & -15.295 & -13.723 & -6.647 & -44.233 & 6.362 \\
\hline $\operatorname{CoVaR} R_{I T A \mid U S A(U)}^{U}$ & 16.206 & 14.622 & 54.686 & 7.539 & 6.517 \\
\hline \multicolumn{6}{|l|}{ Panel F } \\
\hline$V a R_{U K}^{D}$ & -6.504 & -5.988 & -2.095 & -30.289 & 3.326 \\
\hline$V a R_{U K}^{U}$ & 7.837 & 7.391 & 36.246 & 3.421 & 3.305 \\
\hline $\operatorname{CoVaR}_{U K \mid U S A(D)}^{D}$ & -11.883 & -10.986 & -4.458 & -51.605 & 5.692 \\
\hline $\operatorname{CoVaR} R_{U K \mid U S A(U)}^{U}$ & 13.216 & 12.321 & 59.012 & 5.881 & 5.662 \\
\hline
\end{tabular}


First, the risk spillover effects are tested by comparing the cumulative distribution for $\mathrm{CoVaR}$ and the corresponding $\mathrm{VaR}$ of the $\mathrm{G} 7$ stock markets using a bootstrap Kolmogorov-Smirnov (KS) test, in line with Reboredo et al (2016). Table 7 presents the results of upside, downside and asymmetric risk spillover. Our results first indicate that the upside CoVaR is significantly larger than its corresponding VaR, while the downside CoVaR is significantly smaller than its corresponding VaR for five G7 countries. This is consistent with our expectation that there is significant risk spillover from the US to the remaining G7 stock markets, verifying the existence of some potential systemic risk in the global financial market. Second, we test whether upside and downside risk spillover are different for the G7 countries. The upside and downside values of CoVaR normalised by its corresponding VaR are compared. The results in the last column of Table 7 indicate that the magnitude of downside risk spillover is significantly larger than that of upside risk spillover for all the G7 countries. This finding clearly proves an asymmetric effect between upside and downside risk spillover.

Table 7. Tests of risk spillover and asymmetric effects of CoVaRs

\begin{tabular}{|c|c|c|c|}
\hline Symbol & Downside risk spillover & Upside risk spillover & Asymmetric effect \\
\hline $1 \mid 2$ & $\begin{array}{l}H_{0}: \operatorname{CoVaR}_{1 \mid 2 D}^{D}=\operatorname{VaR}_{1}^{D} \\
H_{1}: \operatorname{CoVaR}_{1 \mid 2 D}^{D}<\operatorname{VaR}_{1}^{D}\end{array}$ & $\begin{array}{l}H_{0}: \operatorname{CoVaR}_{1 \mid 2 U}^{U}=\operatorname{VaR}_{1}^{U} \\
H_{1}: \operatorname{CoVaR}_{1 \mid 2 U}^{U}>\operatorname{VaR}_{1}^{U}\end{array}$ & $\begin{array}{l}H_{0}: \frac{\operatorname{CoVaR}_{1 \mid 2 D}^{D}}{\operatorname{VaR}_{1}^{D}}=\frac{\operatorname{CoVaR}_{1 \mid 2 U}^{U}}{\operatorname{VaR}_{1}^{U}} \\
H_{1}: \frac{\operatorname{CoVaR}_{1 \mid 2 D}^{D}}{\operatorname{VaR}_{1}^{D}}>\frac{\operatorname{CoVaR}_{1 \mid 2 U}^{U}}{\operatorname{VaR}_{1}^{U}}\end{array}$ \\
\hline CAN|USA & $0.910 * * *$ & $0.923 * * *$ & $0.665 * * *$ \\
\hline FRA|USA & $0.863 * * *$ & $0.507 * * *$ & $0.977 * * *$ \\
\hline JPN|USA & $0.358 * * *$ & $0.357 * * *$ & $0.134 * * *$ \\
\hline ITA|USA & $0.426 * * *$ & $0.439 * * *$ & $0.102 * * *$ \\
\hline UK|USA & $0.556 * * *$ & $0.562 * * *$ & $0.647 * * *$ \\
\hline
\end{tabular}

Note: ${ }^{\text {a }}$ and ${ }^{* *}$ denote significance levels of $5 \%$ and $1 \%$, respectively. 

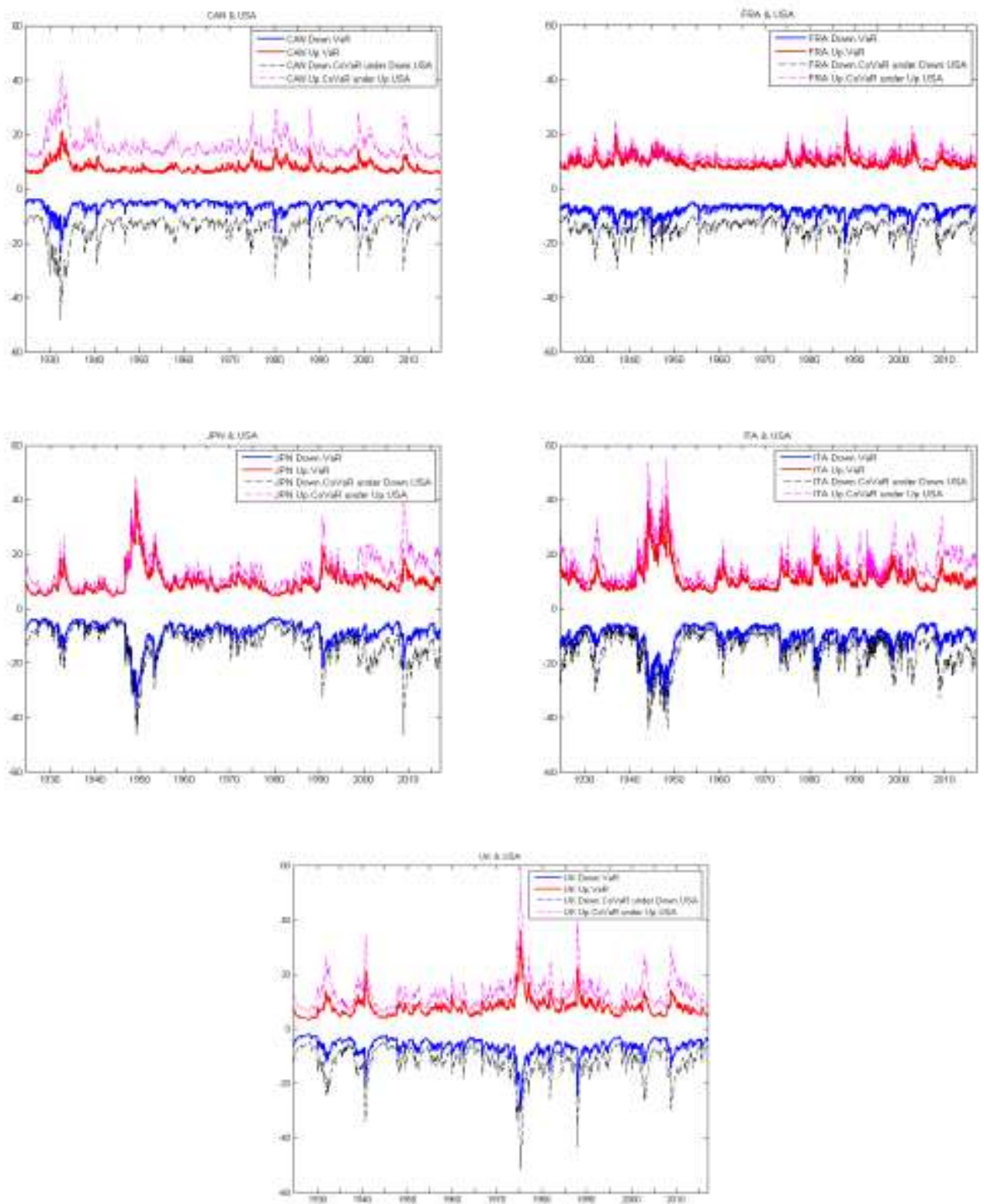

Figure 4. VaRs and CoVaRs for the G7 stock returns conditional on the VaR for the US stock

Finally, Figure 4 presents the dynamics of upside and downside VaRs and CoVaRs for the G7 stock markets. The shape of the CoVaRs in each country is comparatively different, which means that the impact of extreme risk in the US market on extreme risk in the G7 markets is unique for each individual country. Specifically, the gap between CoVaR and VaR in CAN is relatively larger than that in other countries. In particular, the gap between downside CoVaR and VaR is intuitively larger than the upside CoVaR and VaR, as verified by the asymmetric tests shown in 
Table 7. Moreover, there are some obviously unequal spikes in the dynamic CoVaRs for each stock market pair, which were induced by specific economic events. For example, there were sudden spikes in CoVaRs due to the Great Depression in the US in 1933; World War II in 1945; the three oil crisis in 1973, 1979 and 1990; and the 2008 global financial crisis.

\subsection{Asymmetric risk spillover to and from the US stock market}

In this section, we estimate the CoVaR for the US stock market conditional on the VaR for G7 stock returns at a 95\% confidence level. Table 8 presents the results of asymmetric tests performed to determine risk spillover to and from the US stock market. This analysis allows us to determine which country can exert a greater influence on other countries from a risk perspective. Surprisingly, there are significant asymmetric effects, and the magnitude of risk spillover from other G7 stock markets to the US stock market is larger than that from the US stock market to the remaining G7 stock markets. One possible reason is that the VaRs of the G7 stock markets are larger than the VaR of the US stock market, as presented in Table 6.

Table 8. Asymmetric test for risk spillover to and from the US stock market

\begin{tabular}{|c|c|c|}
\hline Symbol & Downside asymmetry & Upside asymmetry \\
\hline $1 \mid 2$ & $\begin{array}{l}H_{0}: \frac{\operatorname{CoVaR}_{1 \mid 2(D)}^{D}}{\operatorname{VaR}_{1}^{D}}=\frac{\operatorname{CoVaR}_{2 \mid 1(D)}^{D}}{\operatorname{VaR}_{2}^{D}} \\
H_{1}: \frac{\operatorname{CoVaR}_{1 \mid 2(D)}^{D}}{\operatorname{VaR}_{1}^{D}}<\frac{\operatorname{CoVaR}_{2 \mid 1(D)}^{D}}{\operatorname{VaR}_{2}^{D}}\end{array}$ & $\begin{array}{l}H_{0}: \frac{\operatorname{CoVaR}_{1 \mid 2(D)}^{U}}{\operatorname{VaR}_{1}^{U}}=\frac{\operatorname{CoVaR}_{2 \mid 1(D)}^{U}}{\operatorname{VaR}_{2}^{U}} \\
H_{1}: \frac{\operatorname{CoVaR}_{1 \mid 2(D)}^{U}}{\operatorname{VaR}_{1}^{U}}<\frac{\operatorname{CoVaR}_{2 \mid 1(D)}^{U}}{\operatorname{VaR}_{2}^{U}}\end{array}$ \\
\hline CAN|USA & $0.388^{* * *}$ & $0.173 * * *$ \\
\hline FRA|USA & $0.776 * * *$ & $0.347 * * *$ \\
\hline JPN|USA & $0.190 * * *$ & $0.050^{*}$ \\
\hline ITA|USA & $0.253^{* * *}$ & $0.111^{* * *}$ \\
\hline UK|USA & $0.492 * * *$ & $0.275^{* * *}$ \\
\hline
\end{tabular}

\section{Conclusions}

This paper analyses the risk spillover effect between the US stock market and the 
remaining G7 stock markets using time-varying copula models with Markov switching and data that covers more than 100 years and numerous crises. The CoVaRs of each stock market are measured to investigate risk spillover with upside, downside and asymmetric effects between the US and the remaining six G7 countries.

Our models reveal the dynamic dependence structure of the stock markets with two different regimes. Generally speaking, the dependences between the US and the remaining G7 stock markets are positive. The whole sample dependence of Canada and USA is the highest of the five pairs. Two distinct dependence regimes, named high dependence and low dependence, are verified by different dependence parameters across regimes. The estimated smoothing probabilities imply that the dependence structure between the US and the remaining G7 stock markets changes over time. The status of a dependence regime is persistent and highly correlated with changes in tail dependence. Moreover, the probability that dependence relations between the US and G7 stock markets will enter a high dependence regime has increased in the 21 st century, especially during the 2008 financial crisis.

Estimation of CoVaRs verified that there is significant risk spillover between the US and the remaining G7 stock markets. This means that the VaR for one stock market conditional on the VaR for another stock market is significantly larger than the upside VaR and significantly smaller than the downside VaR. This finding can provide evidence that a country's risk may trigger global systemic risk. Moreover, there is an asymmetric effect between upside and downside risk spillover, and the magnitude of downside risk spillover is larger than that of upside risk spillover. This conclusion aligns with our expectation that asset decline is more likely to lead to a wider range of financial contagion. Finally, comparison of the risk spillover to and from the US stock market revealed that the impact of CAN, FRA, GER, JPN, ITA and UK on the US 
stock market is greater than that of the US on the remaining six G7 countries.

Important economic and financial implications can be derived from this paper. First, our main results suggest that any negative shock affecting one of the national stock markets will rapidly affect other stock markets, and thus, increase global systemic risk. Positive shocks, on the contrary, are not so rapidly spread among different stock markets. Third, the results point to an increase in the risk spillovers in the $21^{\text {st }}$ century compared to previous periods. From a regulatory point of view, this new context explains, for example, the recent Basel III international regulatory framework. Furthermore, our results suggest that negative shocks originated in CAN, FRA, GER, JPAN, ITA and the UK have more negative effects on the US stock market than those shocks originated in the US have on the remaining G7 countries, so that, stronger policies should be directed to counteract shocks which could negatively affect the stock markets in these countries. From the investors' point of view, the results also suggest that higher diversification opportunities in G7 stock markets can be found in periods of positive stock market returns than in those of negative returns.

This paper provides a new analytical tool for investigating nonlinear dynamic dependence, asymmetry and risk spillover. Our findings have important implications for financial investors and risk managers in terms of risk prediction and portfolio strategy. In particular, our useful information regarding upside and downside risk can help develop asymmetric trading strategies.

\section{Acknowledgements}

Qiang Ji acknowledges support from the National Natural Science Foundation of China under Grant No. 91546109, No. 71203210; and Youth Innovation Promotion Association of Chinese Academy of Sciences (Grant: Y7X0231505). Juncal Cunado 
acknowledges financial support from Ministerio de Economia y Competitividad (ECO2017-83183-R). We would also like to thank an anonymous referee for many helpful comments. However, any remaining errors are solely ours.

\section{References}

Adrian, R., Brunnermeier, M.K., 2011. CoVaR. NBER Working Paper 17454.

Ahnert, T., Bertsch, C. 2015. A wake-up call theory of contagion. Sveriges Riksbank Working Paper Series 319.

Aït-Sahalia; Y., Hurd, T., 2016. Portfolio choice in markets with contagion. Journal of Financial Econometrics 14, 1-28.

Ang, A., Bekaert, G., 2002. International asset allocation with regime shifts. Review of Financial Studies 15, 1137-1187.

Ang, A., Chen, J., 2002. Asymmetric correlations of equity portfolios. Journal of Empirical Economics 63, 443-494.

Ang, A., Timmermann, A., 2011. Regime changes and financial markets. NBER Working Paper 17182.

Asgharian, H., Hess, W., Liu, L. 2013. A spatial analysis of international stock market linkages. Journal of Banking and Finance 37, 4738- 4754.

Aye, G.C., Balcilar, M., and Gupta, R. (2017). International stock return predictability: Is the role of US time-varying? Empirica 44(1), 121-146.

Bae, K.H., Karolyi, A., Stulz, R., 2003. A new approach to measuring financial contagion. Review of Financial Studies 16, 717-763.

Bae, K.H., Zhang, X., 2015. The cost of stock market integration in emerging markets. Asia Pacific Journal of Financial Studies 44, 1-23.

Bae, J., Kim, C.J., Nelson, C., 2007. Why are stock returns and volatility negatively correlated? Journal of Empirical Finance 13, 41-58. 
Balcilar, M., Demirer, R., Hammoudeh, S., Nguyen, D.K., 2016. Risk spillovers across the energy and carbon markets and hedging strategies for carbon risk. Energy Economics 54, 159-172.

Bartram, S.M., Taylor, S.J., Wang, Y.H., 2007. The euro and European financial market dependence. Journal of Banking and Finance 31, 1461-1481.

Beirne, J., Caporale, G.M., Schulze-Ghattas, M., Spagnolo, M., 2010. Global and regional spillovers in emerging stock markets. A multivariate GARCH-in-mean analysis. Emerging Markets Review 11, 250-260.

Bekaert, G., Harvey, C.R., 2003. Emerging markets finance. Journal of Empirical Finance 10, 3-55.

Bekaert, G., Harvey, C.R., Ng, A., 2005. Market integration and contagion. Journal of Business 78, 39-69.

Bekaert, G., Hodrick, R.J., Zhang, X., 2009. International stock return comovements. Journal of Finance 64, 2591-2626.

Bekaert, G., Ehrmann, M., Fratzscher, M., Mehl, A., 2014. The global crisis and equity market contagion. Journal of Finance 69, 2597-2649.

Billio, M., Lo Duca, M., and Pelizzon, L., 2005. Contagion Detection with Switching Regime Models: A Short and Long Run Analysis. SSRN eLibrary.

Boyer, B.H., Kumagai, T., Yuan, K., 2006. How do crises spread? Evidence from accesible and inaccesible stock indexes. Journal of Finance 61, 957- 1003.

Brunnermeier, M.K., Crocket, A., Persaud, A.D., Shin, H., 2009. The fundamental principles of financial regulation. Geneva London: International Center for Monetary and Banking Studies Centre for Economic Policy Research.

Caporale, G.M., Cipollini, A., Spagnolo, N., 2004. Testing for contagion: a conditional correlation analysis. Journal of Empirical Finance 12, 476-489. 
Chuliá, H., Guillén, M., Uribe, J.M., 2017. Spillovers from the United States to Latin American and G7 stock markets: A VAR quantile. Emerging Markets Review 31, $32-46$.

Corsetti, G., Pesenti, P., Roubini, N., 1999. Paper tigers? A model of the Asian crisis. European Economic Review 43, 1211-1236.

Diebold, F., Yilmaz, K., 2009. Measuring financial asset return and volatility spillovers, with application to global equity markets. Economic Journal 119, $158-171$.

Edwards, S., 2000. Contagion. The World Economy 23, 873-900.

Ehrmann, M., Fratzscher, M., Rigobon, R., 2011. Stocks, bonds, money markets and exchange rates: measuring international financial transmission. Journal of Applied Econometrics 26, 948-974.

Forbes, K.J., 2012. The "Big C": Identifying and mitigating contagion. MIT Sloan Research Paper.

Forbes, K.J., Rigobon, R., 2002. No contagion, only interdependence. Journal of Finance 57, 2223-2261.

Guo, F., Chen, C.R., Huang, Y.S., 2011. Markets contagion during financial crisis: A regime switching approach. Internatinal Review of Economics and Finance 20, 95-109.

Hong, Y., Tu, J., Zhou, G., 2007. Asymmetries in stock returns: statistical tests and economic evaluation. Review of Financial Studies 20, 1547-1581.

Jayasuriya, S., 2011. Stock market correlations between China and its emerging market neighbors. Emergin Markets Review 12, 418-431.

Ji, Q., Bouri, E., Roubaud, D., Shahzad, S.J.H., 2018a. Risk spillover between energy and agricultural commodity markets: A dependence-switching CoVaR-copula 
model. Energy Economics, 75, 14-27.

Ji, Q., Liu, B., Zhao, W., Fan, Y., 2018. Modelling dynamic dependence and risk spillover between all oil price shocks and stock market returns in the BRICS. International Review of Financial Analysis. https://doi.org/10.1016/j.irfa.2018.08.002.

Ji, Q., Liu, B., Fan, Y., 2018. Risk dependence of CoVaR and structural change between oil prices and exchange rates: A time-varying copula model. Energy Economics. https://doi.org/10.1016/j.eneco.2018.07.012.

Joe, H., 1997. Multivariate models and dependence concepts. London: Chapman \& Hall.

Joe, H., Xu, J.J., 1996. The estimation method of inference functions for margins for multivariate models. Technical Report 166. Department of Statistics, University of British Columbia.

Jorion, P., 2006. Value at Risk. McGraw-Hill, $3^{\text {rd }}$ ed.

Kaminski, G.L., Reinhart, C.M., 1999. The twin crisis: the causes of banking and balance of payments problems. American Economic Review 89, 473-500.

Karolyi, G.A., 2003. Does international financial contagion really exist? International Finance 6, 179-199.

Kashyap, A.K., Raghuram, G.R., Stein, J.C., 2008. Rethinking capital regulation. Economic Symposium "Maintaining stability in a changing financial system". Federal Reserve Bank of Kansas City.

Kim, C.J., 1994. Dynamic linear models with Markov-Switching. Journal of Econometrics 60(1-2), 1-22.

Kodres, L.E. and Pritsker, M., 2002. A rational expectations model of financial contagion. Journal of Finance 57, 769-799. 
Kupiec, P., 2002. Calibrating your intuition: capital allocation for market and credit risk. IMF Working Paper 02/99.

Lehkonen, H., 2015. Stock market integration and the global financial crisis. Review of Finance 19, 2039-2094.

Liu, B.Y., Ji, Q., Fan, Y., 2017. A new time-varying optimal copula model identifying the dependence across markets. Quantitative Finance, 17(3), 437-453.

Longin, F., Solnik, B., 2001. Extreme correlation of international equity markets. Journal of Finance 56, 649- 676.

Lopes, J.M., Nunes, L.C., 2012. A Markov regime switching model of crises and contagion: the case of the Iberian countries in the EMS. Journal of Macroeconomics 34, 1141- 1153.

Mensi, W., Hammoudeh, S., Shahzad, S.J.H., Shahbaz, M., 2017. Modeling systemic risk and dependence structure between oil and stock markets using a variational mode decomposition-based copula method. Journal of Banking and Finance 75, 258-279.

Nier, E., 2009. Financial stability frameworks and the role of Central Banks: Lessons from the crisis. IMF Working Paper 09/70.

Ozcan, F.G., Unsal, D.F., 2012. Global financial crisis, financial contagion and emerging markets. IMF Working Paper 12/293.

Patton, A.J., 2006. Modelling the asymmetric exchange rate dependence. International Economic Review 47, 527-556.

Patton, A.J., 2013. Copula methods for forecasting multivariate time series. in Handbook of Economic Forecasting. Oxford: Elsevier, pp. 899-960.

Polanski, A., Stoja, E., 2015. Extreme risk interdependence. Bank of England Staff Working Paper 563. 
Pritsker, M., 2001. The channels for financial contagion. In: Clasessens, S., Forbes, K.J. (eds), International Financial Contagion, Springer, Boston, MA.

Rapach, D.E., Strauss, J.K. and Zhou, G. (2013). International stock return predictability: What is the role of the United States? The Journal of Finance 68(4), $1633-1662$.

Roubini, N., 2003. Contagion. Stern School of Business, New York University.

Reboredo, J.C., Ugolini, A., 2015. Systemic risk in European sovereign debt markets: A CoVaR-copula approach. Journal of International Money and Finance 51, 214-244.

Reboredo, J.C., Rivera-Castro, M.A., Ugolini, A., 2016. Downside and upside risk spillovers between exchange rates and stock prices. Journal of Banking and Finance 62, 76-96.

Silva Filho, O.C., Ziegelmann, F.A., Dueker, M.J., 2012. Modeling dependence dynamics through copulas with regime switching. Insurance: Mathematics and Economics 50(3), 346-356.

Van Rijckeghem. C., Weder, B. 2001. Sources of contagion: is it finance or trade? Journal of International Economics 43, 293-308. 
